\title{
INVENTARISASI SERANGAN HAMA KUTU PUTIH (Mealybug) PADA TANAMAN SINGKONG DI KECAMATAN ROGOJAMPI DAN SINGOJURUH
}

\author{
Syofi Atusholihah, Diah Etika Maharatih Setiarina, Fuad Ardiyansyah \\ Program Studi Biologi, Fakultas Matematika dan Ilmu Pengetahuan Alam \\ Universitas PGRI Banyuwangi \\ Email: syofiatusholihah@gmail.com
}

\begin{abstract}
ABSTRAK
Kutu putih Phenacoccus manihoti Matile-Fererro (Hemiptera: Pseudo-coccidae) merupakan hama yang paling banyak menimbulkan kerusakan pada pertanaman singkong. Kabupaten Banyuwangi khususnya di Kecamatan Rogojampi dan Singojuruh belum pernah dilaporkan mengenai jenis-jenis hama kutu putih yang menyerang pertanaman singkong, hal ini disebabkan karna belum adanya laporan petani tentang pengurangan produksi akibat hama kutu putih dan juga petani belum menyadari akan dampat serangan hama kutu putih pada tanaman singkong. Metode yang digunakan adalah metode deskriptif. Penelitian dilakukan selama dua bulan yaitu pada bulan Mei sampai Juni 2018 di Kecamatan Singonjuruh dan Rogojampi di kebun warga sekitar. Analisis data meliputi keanekaragaman spesies, penentuan kerusakan mutlak, dan kelimpahan jenis. Hasil menunjukan ditemukan spesies Paracoccus marginatus dan Ferrisia virgata. keanekaragaman spesies di Kecamatan Rogojampi $\mathrm{H}^{\prime}=0.725$ dengan kategori rendah, sedangkan pada Kecamatan Singojuruh memiliki total indeks keanekaragaman $\mathrm{H}^{\prime}=0,022$ kategori rendah. Kelimpahan jenis kutu putih di Kecamatan Rogojampi dan Singojuruh didominasi oleh jenis Paracoccus marginatus dengan nilai kelimpahan 1.956 individu di Rogojampi dan 2.390 individu di Singojuruh. Kerusakan mutlak yang disebabkan oleh serangan kutu putih yang ditemukan di Kecamatan Rogojampi pada jenis Paracoccus marginatus adalah 0,602 dan pada jenis Ferrisia virgate yaitu 0,771. Total kerusakan mutlak tanaman singkong yang ada di kecamatan Rogojampi adalah 1,373\% angka tersebut menunjukkan kerusakan sedang pada tanaman singkong. Untuk diwilayah kecamatan singojuruh menunjukkn total kerusakan mutlak tanaman singkong yaitu berjumlah 1,281 angka tersebut menunjukkan kerusakan sedang pada tanaman singkong.
\end{abstract}

Kata kunci: Kutu Putih, Tanaman Singkong, Keanekaragamaan, Tingkat kerusakan 


\section{ABSTRACT}

The mealybug Phenacoccus manihoti Matile-Ferrero (Hemiptera: Pseudococcidae) is a pest that causes the most damage to cassava crops. Banyuwangi Regency, especially in Rogojampi and Singojuruh Districts, has never been reported regarding the types of mealybugs that attack cassava plantations, this is because there are no reports of farmers about reduced production due to mealybugs and farmers are not

aware of the impact of mealybugs on cassava plant. The method used is descriptive method. The research was conducted for two months, from May to June 2018 in Singonjuruh and Rogojampi Districts in the local residents' gardens. Data analysis included species diversity, absolute damage determination, and species abundance. The results showed that Paracoccus marginatus and Ferrisia virgata species were found. Species diversity in the Rogojampi District $\mathrm{H}^{\prime}=0.725$ in the low category, while in the Singojuruh District it has a total diversity index of $\mathrm{H} 0,0=0.022$ in the low category. The abundance of mealybugs in Rogojampi and Singojuruh Districts was dominated by Paracoccus marginatus with an abundance value of 1,956 individuals in Rogojampi and 2,390 individuals in Singojuruh. Absolute damage caused by mealybug infestation found in Rogojampi Subdistrict on the Paracoccus marginatus species was 0.602 and in the Ferrisia virgate species it was 0.771 . The absolute total damage to cassava plants in the Rogojampi sub-district was $1.373 \%$, this figure indicates moderate damage to cassava plants. For the area of Singojuruh sub-district, the absolute total damage to cassava plants is 1,281 , this figure shows moderate damage to cassava plants.

Keywords: White lice, Cassava Plants, Diversity, Damage Level.

\section{PENDAhUluan}

Ubi kayu juga merupakan komoditas tanaman pangan yang turut menyumbang devisa negara melalui kegiatan ekspor. Kementerian Pertanian Republik Indonesia juga menyatakan bahwa Indonesia adalah produsen ubi kayu terbesar ketiga di dunia setelah Nigeria dan Thailand. Dalam lima tahun terakhir produksi ubi kayu Indonesia terancam oleh kehadiran hama baru yaitu kutu putih Phenacoccus manihoti. Phenacoccus manihoti termasuk dalam ordo Hemiptera, famili Pseudococcidae (Rauf, 2014).

Kabupaten Banyuwangi adalah salah satu sentra produksi ubi kayu ke-2 setelah Kabupaten Bondowoso. Pada tahun 2014 produksi ubi kayu di Kabupaten Banyuwangi sebesar 21,582 ton dengan produktivitas sebesar 3,996 ton per hektar. Kecamatan penghasil ubi kayu di Kabupaten Banyuwangi adalah Kecamatan Rogojampi dan Singojuruh. Pada tahun 2014 produksi ubi kayu di Kecamatan 
Rogojampi, 127 ton dengan luas tanam 43 ha. Produksi ubi kayu di Kecamatan Singojuruh sebesar 3,831 ton dengan luas tanam 39 ha (BPS, 2015).

Selama ini di Kabupaten Banyuwangi khususnya di Kecamatan Rogojampi dan Singojuruh belum pernah dilaporkan mengenai jenis-jenis hama kutu putih yang menyerang pertanaman ubi kayu. Hal ini disebabkan belum ada laporan petani tentang pengurangan produksi akibat hama kutu putih dan juga petani belum menyadari akan dampak serangan hama kutu putih pada ubi kayu. Oleh sebab itu belum ada yang peduli terhadap hama tanaman ubi kayu, akan tetapi informasi tentang hama yang menyerang tanaman sangat penting. Diketahui bahwa di Bogor tahun 2010 ditemukan P. manihoti yang merupakan spesies hama kutu putih baru, yang dikhatirkan setelah (berapa tahun hitung dari 2010 hingga sekarang) hingga saat ini dikhawatirkan spesies hama baru ini telah masuk ke Kabupaten Banyuwangi.

\section{METODE PENELITIAN}

\subsection{Rancangan penelitian}

Jenis penelitian ini adalah penelitian deskriptif kuantitatif. Penelian deskriptif kuantitatif merupakan metode dalam meneliti sekelompok manusia, suatu objek, suatu kondisi, suatu sistem pemikiran ataupun suatu kelas peristiwa pada masa sekarang (Nizar, 2018).Metode yang digunakan dalam penelitian ini adalah metode pengamatan langsung dan pengamatan sampel dan melakukan dengan cara memilih batang singkong sebanyak 30 puluh kemudian mencari kutu putih tersebut yang menempel pada tanaman singkong.

Penelitian dilakukan di dua Kecamatan yaitu Kecamatan Rogojampi dan Singojuruh pada bulan mei sampai juni 2018. Lokasi ditentukan metode purposive area, artinya menentukan tempat/daerah penelitian didasarkan atas tujuan-tujuan tertentu. Kriteria dalam menentukan lokasi penelitian yaitu lahan singkong yang memiliki luas lahan minimal 5mx10m atau minimal memiliki 30 tanaman singkong pada setiap lahannya dan yang berumur 2-3 bulan. Lokasi yang dipilih di Kecamatan Rogojampi adalah desa Kedaleman, Kedunen, Warengan. Lokasi yang dipilih di Kecamatan Singojuruh adalah di desa Alas malang, Pasinan dan Padang bulan. Lokasi pengambilan sampel dapat dilihat pada Gambar 2.1 


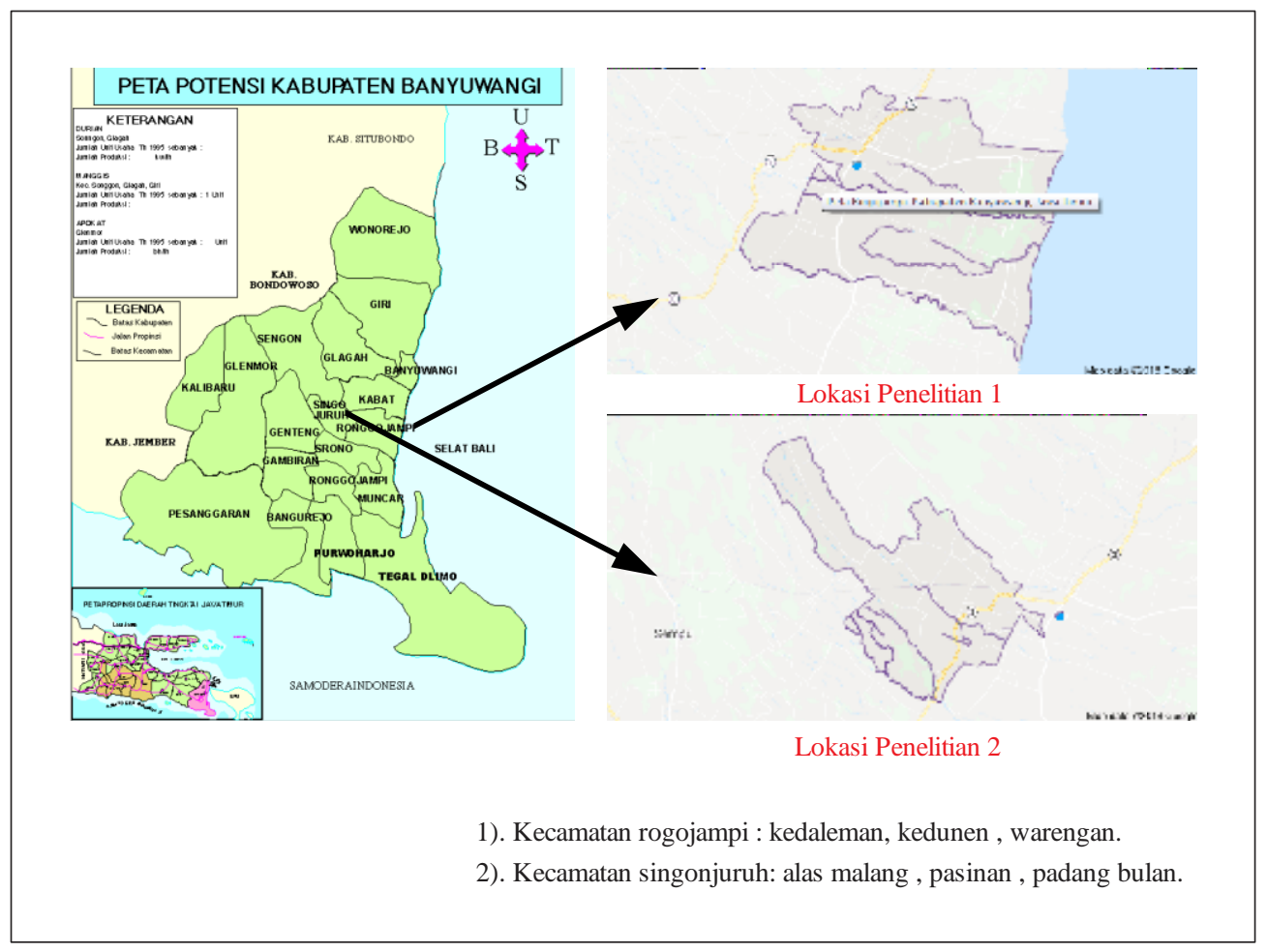

Gambar 2.1 Peta Wilayah Lokasi Penelitian (gambar daerah.blogspot.com)

\subsection{Pengambilan data}

a. Keanekaragaman Spesies

Indeks Shannon-Wiener (Magurran, 2004) digunakan untuk mengetahui keanekaragaman spesies pada setiap habitat, dengan rumus :

$\mathrm{H}^{\prime}=-\Sigma p i \ln p i, \quad \longrightarrow p i=\frac{n i}{N}$

Keterangan :

$$
\begin{aligned}
& \mathrm{H}^{\prime}=\text { Indeks Shannon Wiener } \\
& \mathrm{ni}=\text { Jumlah individu untuk spesies yang diamati } \\
& \mathrm{N}=\text { Jumlah total individu }
\end{aligned}
$$

Indeks keanekaragaman dikelompokkan dalam tiga kriteria, yaitu : apabila $\mathrm{H}^{\prime}<$ 1 , maka keragaman rendah. Selanjutnya apabila $\mathrm{H}^{\prime}=1<\mathrm{H}^{\prime}<3$ makakeanekaragaman sedang dan apabila nilai $\mathrm{H}^{\prime}>3$ maka keanekaragamannya 
tinggi.

b. Penentuan Kerusakan Mutlak

Untuk menilai serangan hama yang menyebabkan kerusakan mutlak (dianggap mutlak) digunakan rumus natawigena,(1989) sebagai berikut :

$$
p=\frac{\mathrm{a}}{\mathrm{a}+\mathrm{b}} \times 100 \%
$$

Dimana : $\mathrm{P}=$ intensitas kerusakan $(\%)$

$\mathrm{a}=$ banyak pohon ( daun dan batang ) yang terserang ,

$\mathrm{b}=$ banyaknya pohon ( daun dan batang ) tidak terserang .

c. Kelimpahan Jenis

Kelimpahan Jenis serangga kutu putih merupakan jumlah total spesies pada suatu komunitas. Kelimpahan jenis dapat dihitung dengan menggunakan rumus Densitas (Campbell et al., 2004).

$$
\mathrm{D}=\frac{n i}{s i}
$$

Keterangan :

$\mathrm{D}=$ Density (kelimpahan jenis)

ni $=$ Numerus (Jumlah individu dari jenis ke-i)

si $=$ Spatum (Jumlah luasan jenis ke-i ditemukan)

\section{HASIL DAN PEMBAHASAN}

Hasil penelitian menunjukan bahwa jenis kutu putih yang ditemukan adalah Paracoccus marginatus dan Ferrisia virgata. Jumlah spesies di dominasi dari jenis Paracoccus marginatus. Hasil kutu putih yang ditemukan dalam penelitian dapat dilihat pada gambar3.1.

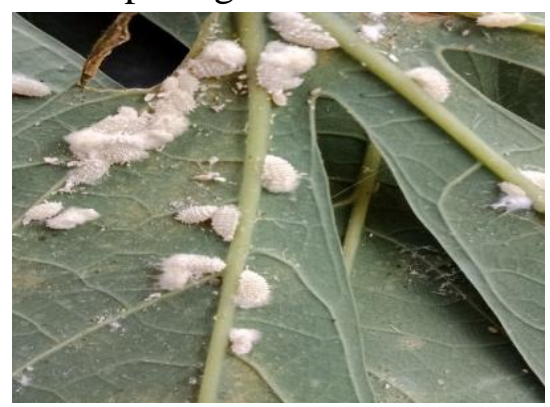

Gambar 3.1 jenis Paracoccus marginatus

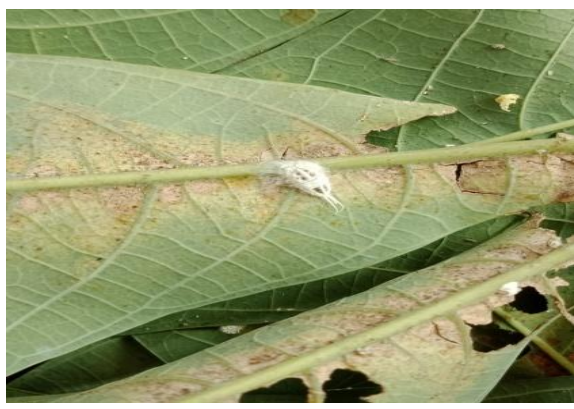

Gambar 3.2 jenis Ferrisia virgata

\begin{tabular}{l|l}
\hline Inventarisasi serangan hama kutu putih (mealybug) pada tanaman singkong di kecamatan rogojampi dan & 18
\end{tabular} singojuruh 
3.1. Data Jumlah Spesies Kutu Putih (Mealybug) yang ditemukan

Berikut merupakan data jumlah spesies kutu putih yang ditemukan di Kecamatan Rogojampi ditampilkan pada tabel 3.1.

Tabel 3.1. Data Jumlah Spesies Kutu Putih di Kecamatan Rogojampi

\begin{tabular}{ccccccc}
\hline \multirow{2}{*}{ Df } & \multicolumn{3}{c}{ Paracoccus marginatus } & \multicolumn{3}{c}{ Ferrisia virgata } \\
\cline { 2 - 7 } & Kedaleman & Kedunen & Warengan & Kedaleman & Kedunen & Warengan \\
\hline Ulg 1 & 258 & 179 & 289 & 13 & 5 & 10 \\
\hline Ulg 2 & 240 & 150 & 220 & 8 & 3 & 9 \\
\hline Ulg 3 & 235 & 155 & 230 & 6 & 0 & 4 \\
\hline Tot. & 733 & 484 & 739 & 27 & 8 & 23 \\
\hline
\end{tabular}

Keterangan : Df $=$ Different $($ Perbedaan $)$

Berdasarkan data jumlah spesies kutu putih Paracoccus marginatus di kecamatan Rogojampi di desa Kedaleman memiliki nilai total sedang yaitu 733 individu, kemudian di desa Kedunen memiliki nilai terendah dengan total 484 individu, pada desa Warengan sangat memiliki nilai yang tinggi yaitu ber total 739 individu. Pada jenis Ferrsia virgatadi desa Kedaleman memiliki nilai yang cukup tinggi dan di desa kedunen memiliki nilai terendah dengan total 8 individu. Dan di desa Warengan memiliki nilai total 23 individu. Maka dari dua jenis spesies kutu putih tersebut Paracoccus marginatus dan Ferrsia virgata sangat memiliki nilai yang bermacam macam atau bervariasi dari nilai total spesies yang paling tinggi untuk Paracoccus marginatus ditunjukkan di desa Warengan dan untuk spesies Ferrsiavirgata menunjukkan nilai terendah ada di desa Kedunen

Tabel 3.2. Data Jumlah Spesies Kutu Putih di Kecamatan Singojuruh

\begin{tabular}{lcccccc}
\hline \multirow{2}{*}{ Df } & \multicolumn{2}{c}{ Paracoccus marginatus } & \multicolumn{3}{c}{ Ferrisia virgata } \\
\cline { 2 - 7 } & Alasmalang & Pasinan & Padangbulan & Alasmalang & Pasinan & Padangbulan \\
\hline Ulg 1 & 320 & 250 & 152 & 10 & 6 & 2 \\
\hline Ulg 2 & 305 & 290 & 210 & 10 & 4 & 0 \\
\hline Ulg 3 & 330 & 283 & 250 & 9 & 0 & 0 \\
\hline Tot. & 955 & 823 & 612 & 29 & 10 & 2
\end{tabular}


Keterangan : Df : Different ( perbedaan)

Berdasarkan pada data jumlah spesies Paracoccus marginatusdi kecamatan Singonjuruh di desa alas malang mendapatkan total sebanyak 955 individu, kemudian di desa pasinan mendapatkan nilai jumlah total jenis spesies Paraccocus marginatussebanyak 823 individu. Dan di desa padang bulan memiliki nilai total yang rendah yaitu 612. Pada jenis spesies Ferrsia virgata di desa Alas malang memiliki nilai yang cukup tinggi yaitu 29 individu. kemudian di desa Pasinan memiliki nilai sedang yaitu jumlah total 10 individu. Pada desa Padang bulan mendapatkan nilai total terendah yaitu 2 individu. Dari kedua jenis spesies kutu putih Paracoccus marginatus dan Ferrsia virgata sangat memiliki nilai yang berbeda.

\subsection{Hasil Analisa Data}

Dari hasil analisa keanekaragam spesies pada kutu putih yang ditemukan di Kecamatan Rogojampi dan Singojuruh adalah sebagai berikut :

\subsubsection{Data Keanekaragaman Spesies}

Tabel. 3.3. Keanekaragaman Spesies Kutu Putih di Kecamatan Rogojampi

\begin{tabular}{lcccccccc}
\hline \multirow{2}{*}{ Lokasi } & $\mathrm{N}$ & \multicolumn{2}{c}{$\mathrm{Ni}$} & \multicolumn{2}{c}{$\mathrm{Pi}$} & $\mathrm{pi}^{*} \ln \mathrm{pi}$ & $\mathrm{H}^{\prime}$ \\
\cline { 3 - 8 } & & P.m & F.v & P.m & F.v & P.m & F.v & \\
\hline RGJ & & & & & & & & \\
\hline Kedaleman & 760 & 733 & 27 & 0,964 & 0,036 & 0,035 & 0,119 & 0,372 \\
\hline Kedunen & 492 & 484 & 8 & 0,984 & 0,016 & 0,016 & 0,067 & 0,218 \\
\hline Warengan & 762 & 739 & 23 & 0,970 & 0,030 & 0,030 & 0,106 & 0,135 \\
\hline
\end{tabular}

Keterangan $:$ F.v = Ferrisia virgatedan P.m = Paracoccus marginatus

Pada data keanekeragaman spesies kutu putih Paracoccus marginatus yang ditemukan di kecamatan Rogojampi di desa Warengan memiliki nilai indeks keanekaragaman yaitu dari nilai terendah 484 individu dan nilai yang tertinggi yaitu bertempat di desa Warengan bertotal nilai 739 individu. Pada jenis spesies Ferrsia virgata di desa Kedaleman memiliki nilai tertinggi yaitu 27 individu. Desa Kedunen memiliki nilai paling rendah dengan total 8 individu. Jadi diantara kedua spesies kutu putih Paracoccus marginatus dan Ferrsia virgata tersebut dijumlah total individunya 
dan dari 3 desa itu nilai dari 2 spesies yang paling tinggi berada di desa Kedaleman yang bernilai $0,372 \%$ dari hasil nilai total terendah dari 2 jenis spesies kutu putih terdapat di desa Warengan dengan total nilai $0,135 \%$.

Tabel. 3.4. Keanekaragaman Spesies Kutu Putih di Kecamatan Singojuruh

\begin{tabular}{ccccccccc}
\hline \multirow{2}{*}{ Lokasi } & $\mathrm{N}$ & \multicolumn{2}{c}{$\mathrm{Ni}$} & \multicolumn{2}{c}{$\mathrm{Pi}$} & \multicolumn{2}{c}{$\mathrm{pi}^{*} \ln \mathrm{pi}$} & \multirow{2}{*}{$\mathrm{H}^{\prime}$} \\
\cline { 3 - 7 } & & P.m & F.v & P.m & F.v & P.m & F.v & \\
\hline Singojuruh & & & & & & & & \\
\hline Alasmalang & 984 & 955 & 29 & 0.971 & 0.029 & 0.029 & 0.104 & 0.219 \\
\hline Pasinan & 833 & 823 & 10 & 0.988 & 0.012 & 0.012 & 0.053 & 0,087 \\
\hline Padangbulan & 614 & 612 & 2 & 0.996 & 0.003 & 0.003 & 0.019 & 0,022 \\
\hline
\end{tabular}

Keterangan : F.v = Ferrisia virgatedan P.m = Paracoccus marginatus

Berdasarkan pengamatan dari kecamatan Singojuruh di desa Alas malang pada jenis Paracoccus marginatus memiliki nilai yang sangat tinggi yaitu 955 individu. untuk di desa Padang bulan memiliki nilai yg sangat rendah yaitu 612 individu. Kemudian untuk spesies Ferrisia virgata memiliki nilai keanekaragaman terendah di desa Padang bulan dengan nilai 2 untuk spesies ferrisia virgata dan yang paling tinggi di desa Alas malang dengan nilai 29 spesies ferrisia virgate

\subsection{Kelimpahan Jenis atau Dominasi}

Tabel. 3.5. Data Indeks Kelimpahan Jenis Kutu Putih di Kecamatan Rogojampi

\begin{tabular}{|c|c|c|c|c|c|}
\hline \multirow{2}{*}{ Nama Spesies } & \multicolumn{3}{|c|}{ Ulangan } & \multirow{2}{*}{$\mathrm{Si}$} & \multirow{2}{*}{$\mathrm{D}$} \\
\hline & 1 & 2 & 3 & & \\
\hline Paracoccus marginatus & 733 & 484 & 739 & 1956 & 0.971 \\
\hline F.Ferrisia virgata & 27 & 8 & 23 & 58 & 0.029 \\
\hline Total & 760 & 492 & 762 & 2014 & 1 \\
\hline
\end{tabular}

Keterangan : $\mathrm{Si}=\operatorname{spantum}($ jumlah luasan jenis ke $-\mathrm{I}$ ), D = kelimpahan jenis

Berdasarkan data indeks kelimpahan jenis kutu putih Paracoccus marginatus di kecamatan Rogojampi mempunyai nilai tinggi dari jenis ketiga pengulangan untuk 
spesies Paracoccus marginatus yang bernilai total 1.956 dan kemudian dijadikan rata-rata 0,971. Untuk spesies kutu putih Ferrisia virgata memiliki nilai terendah yaitu 58 dan kemudian dijadikian rata-rata 0,029 dari tiga pengulangan.

Tabel. 3.6. Data Indeks Kelimpahan Jenis Kutu Putih di Kecamatan Singojuruh

\begin{tabular}{|c|c|c|c|c|c|}
\hline \multirow{2}{*}{ Nama Spesies } & \multicolumn{3}{|c|}{ Ulangan } & \multirow{2}{*}{$\mathrm{Si}$} & \multirow{2}{*}{$\mathrm{D}$} \\
\hline & 1 & 2 & 3 & & \\
\hline Paracoccus marginatus & 955 & 823 & 612 & 2390 & 0,983 \\
\hline F. Ferrisia virgata & 29 & 10 & 2 & 41 & 0,016 \\
\hline Total & 984 & 833 & 614 & 2431 & 1 \\
\hline
\end{tabular}

Keterangan : $\mathrm{Si}=$ spantum ( jumlah luasan jenis ke-I ), D = kelimpahan jenis

Berdasarkan pada Tabel 3.6 terlihat bahwa indek kelimpahan spesies kutu putih yang ditemukan di Kecamatan Singojuruh pada jenis Paracoccus marginatusadalah 0,983dan pada jenis Ferrisia virgateyaitu 0,016.

Berdasarkan hasil penelitan kelimpahan jenis kutu putih di Kecamatan Rogojampi dan Singojuruh didominasi oleh jenis Paracoccus marginatusakan tetapi nilai kelimpahan antara kecamatan Rogojampi dan Singojuruh berbeda, perbedaan tersebut dikarenakan oleh faktor iklim seperti curah hujan, suhu, dan kelembaban.Herren dan Hennessey (2013).

\subsection{Kerusakan Mutlak}

Adapun data kerusakan mutlak yang disebabkan oleh kutu putih adalah sebagai berikut :

Tabel. 3.7. Data Indeks Kerusakan Mutlak di Kecamatan Rogojampi

\begin{tabular}{cccccc}
\hline Nama Spesies & $\mathrm{A}$ & $\mathrm{B}$ & $\mathrm{a}+\mathrm{b}$ & Persentase \% & $\mathrm{P}$ \\
\hline Paracoccus marginatus & 733 & 484 & 1217 & $100 \%$ & 0,602 \\
\hline Ferrisia virgata & 27 & 8 & 35 & $100 \%$ & 0,771 \\
\hline Total & 760 & 492 & 1252 & $100 \%$ & 1,373
\end{tabular}

Keterangan $: \mathrm{a}=$ jenis hama kutu putih Paracoccus marginatus, $\mathrm{b}=$ jenis hama kutu putih Ferrisia virgate, $\mathrm{P}=$ nilai presentase

Berdasarkan pada Tabel 3.7 terlihat bahwa indek tanaman singkong yang mengalami kerusakan mutlak yang disebabkan oleh kutu putih yang ditemukan di Kecamatan Rogojampi pada jenis Paracoccus marginatusadalah0,602dan pada jenis Inventarisasi serangan hama kutu putih (mealybug) pada tanaman singkong di kecamatan rogojampi dan $\mid 22$ singojuruh 
Ferrisia virgateyaitu 0,771 , total kerusakan mutlak tanaman singkong yang ada di kecamatan Rogojampi adalah 1,373\%, angka tersebut menunjukkan kerusakan sedang pada tanaman singkong karena ada awal bercak kekuningan (sekitar 10\%) pada beberapa daun bawah dan daun tengah.

Tabel. 3.8. Data Indeks Kerusakan Mutlak di Kecamatan Singojuruh

\begin{tabular}{cccclc}
\hline Nama Spesies & $\mathrm{a}$ & $\mathrm{B}$ & $\mathrm{a}+\mathrm{b}$ & Persentase \% & $\mathrm{P}$ \\
\hline Paracoccus marginatus & 955 & 823 & 1778 & $100 \%$ & 0,537 \\
\hline Ferrisia virgata & 29 & 10 & 39 & $100 \%$ & 0,743 \\
\hline Total & 984 & 833 & 1817 & $100 \%$ & 1,281
\end{tabular}

Keterangan : $\mathrm{a}=$ jenis hama kutu putih Paracoccus marginatus, $\mathrm{b}=$ jenis hama kutu putih Ferrisia virgate, $\mathrm{P}=$ nilai presentase

Berdasarkan pada Tabel 3.8 terlihat bahwa indek tanaman singkong yang mengalami kerusakan mutlak yang disebabkan oleh kutu putih yang ditemukan di Kecamatan Singojuruh pada jenis Paracoccus marginatusadalah0,537dan pada jenis Ferrisia virgateyaitu 0,743 , total kerusakan mutlak tanaman singkong yang ada di kecamatan Singojuruh adalah 1,281\%, angka tersebut menunjukkan kerusakan sedang pada tanaman singkong karena ditandai dengan adanyaawal bercak kekuningan (sekitar 10\%) pada beberapa daun bawah dan daun tengah.

\section{KESIMPULAN DAN SARAN}

\subsection{Kesimpulan}

Berdasarkan nilai penelitian di dapatkan bahwa pada daerah kecamatan Singonjuruh dan Rogojampi jenis hama kutu yang paling mendominasi untuk nilai tertinggi di kecamatan Rogojampi berada di desa kedaleman dengan nilai total individu kutu putih jenis Paracoccus marginatus dan Ferrisia virgata 760 dengan rata-rata 0,372 dan untuk nilai terendah di desa warengan memiliki total individu kutu putih jenis Paracoccus marginatus dan Ferrisia virgata 762 dengan rata-rata 0,135. Dan untuk keankeragaman kutu putih jenis di kecamatan Singonjuruh yang tertinggi berada didesa alasmalang yang bernilai total individu kutu putih jenis Paracoccus marginatus 984 dan Ferrisia virgata ngan rata-rata 0,219, untuk nilai terendah ada di desa padang bulan jenis kutu puth Paracoccus marginatus dan Ferrisia virgata 614 dengan rata-rata 0,022 . Berdasarkan penghitungan tingkat kerusakan mutlak serangan hama kutu putih pada tanaman singkong di kecamatan Rogojampi yakni sebesar 1,373\% dan di kecamatan Singonjuruh sebesar 1,286\%. Dari data tersebut bahwa 
dapat disimpulkan tingkat kerusakan mutlak kutu putih yang tertinggi berada di kecamatan Rogojampi.

\subsection{Saran}

Dengan adanya penelitian ini diharapkan dapat dilanjutkan dengan pola untuk upaya pengendalian serangan kutu putih di kecamatan lain.

Penelitian lebih lanjut masih dibutuhkan untuk mendapatkan informasi mengenai keanekaragaman dan kerusakan mutlak pada tumbuhan singkong, Informasi mengenai tentang inventarisasi serangan kutu putih (mealybug) pada tanaman singkong.

\section{REFERENSI}

Badan Pusat Statistik (BPS). 2015. Produksi Ubi Kayu Menurut Provinsi (ton), 19932015. Badan Pusat Statistik. Jakarta Pusat.

Le Ru B. 1986. Epizootiology of the entomophthoraceous fungus Neozygitesfumosa in a population of the cassava mealybug, Phenacoccusmanihoti (Homoptera: Pseudococcidae). Entomophaga. 31:79-90.

Magurran, AE. 2004. Measuring Biological Diversity. Blackwell Science Ltd. Oxford

Rauf A. 2014. Invasi kutu putih Phenacoccus manihoti. Di dalam: Seminar Kutu putih vs Parasitoid: Pengelolaan hama asing invasif berbasis ekologi. Bogor 24 Sep 2014.

Rauf, A. 2008 .Hama kutu putih Paracoccus marginatus.Pusat Penelitian Ilmu Hama Tanaman.Institut Pertanian Bogor.

Schulthess F, Baumgartner JU, Herren HR. 1987. Factors influencing the life table statistics of the cassava mealybug Phenacoccus manihoti. Int J TropInsect Sci. 8(4-6):851-856.

Nizar, samsul. Hasibuan, Zainal Efendi. (2018). Pendidik Ideal. Depok: Prenadamedia Group. 